disease or aged $<18$ yrs or other reasons. The 311 study patients were interviewed $3.7 \pm 1.88$ yrs (maximum range 1.1-6.3 yrs) after the diagnosis. In total, 190 (61\%, 95\% confidence interval (CI) 55-67) patients confirmed a smoking history (active or former) at the time of pulmonary embolism, of whom $94(30 \%, 95 \%$ CI 25-36) patients were actively smoking. Out of these 94 patients, 32 (35\%, 95\% CI 25-45) had successfully quit smoking in the first year following the diagnosis. Overall, only two $(0.64 \%, 95 \%$ CI $0.08-2.3)$ patients started smoking after the diagnosis of pulmonary embolism. The percentage of quitters was not associated with age in the pulmonary embolism cohort.

Analysis of the control group showed that of the 117,100 population controls randomly selected between 2001 and 2007, $71,614(61 \%, 95 \%$ CI $60-61 \%)$ were current or former smokers and $34,177(29 \%, 95 \%$ CI $28-30 \%)$ were active smokers. There were no significant differences between the fraction of (active) smokers between the patients at the time of the pulmonary embolism and the controls (odds ratio (OR) 1.05, 95\% CI $0.82-1.34$ ). According to the registry, $4-5 \%$ (maximum) of the smokers were able to successfully quit yearly. If $5 \%$ was assumed, successful smoking cessation occurred in 1,709 of the 34,177 active smokers, which is significantly lower compared with the patient cohort ( $\mathrm{p}<0.001$; OR 10.3, 95\% CI 6.88-15.4).

Our data demonstrate that a pulmonary embolism is a signal to quit smoking in a significant proportion of patients (35\%), even without a specific intervention. In addition, randomly selected controls proved to have comparable smoking habits but a significantly smaller proportion of them was able to quit smoking successfully.

Our study has limitations. We could only interview patients who survived the pulmonary embolism and were willing to return to our hospital for a follow-up visit. Also, we have not verified with additional testing whether both the pulmonary embolism patients and the population controls actually stopped smoking. Nevertheless, all data were assessed prospectively in a large cohort. Further studies should focus on the reasons for smoking cessation, the relationship between smoking (cessation) and the occurrence of arterial thrombotic events in the clinical course of pulmonary embolism, and measures to further increase the number of patients quitting smoking.

\section{F.A. Klok*, I.C.M. Mos*, J.T. Tamsma*, K.W. van Kralingen and M.V. Huisman*}

*Section of Vascular Medicine, Dept of General Internal Medicine - Endocrinology, and "Dept of Pulmonary Medicine, Leiden University Medical Center, Leiden, The Netherlands.

\section{STATEMENT OF INTEREST}

None declared.

\section{REFERENCES}

1 Rigotti NA, Singer DE, Mulley Jr AG, Thibault GE. Smoking cessation following admission to a coronary care unit. J Gen Intern Med 1991; 6: 305-311.

2 Becattini C, Agnelli G, Prandoni P, et al. Prospective study on cardiovascular events after acute pulmonary embolism. Eur Heart J 2005; 26: 77-83.

3 Prandoni P, Ghirarduzzi A, Prins $\mathrm{MH}$, et al. Venous thromboembolism and the risk of subsequent symptomatic atherosclerosis. J Thromb Haemost 2006; 4: 1891-1896.

4 Sørensen HT, Horvath-Puho E, Pedersen L, Baron JA, Prandoni P. Venous thromboembolism and subsequent hospitalisation due to acute arterial cardiovascular events: a 20-year cohort study. Lancet 2007; 370: 1773-1779.

5 TNS NIPO. Continu Onderzoek Rookgewoonten 2001-2007. Personen van 15 jaar en ouder. Onderzoek in opdracht van STIVORO voor een rookvrije toekomst [Ongoing Study Smoking Habits 2001-2007. Persons Over 15 Years Old. Study by Request of STIVORO Towards a Smoke-free Future]. Amsterdam, TNS NIPO, 2008.

DOI: $10.1183 / 09031936.00182808$

\title{
Poverty and tuberculosis: is it truly a simple inverse linear correlation?
}

\section{To the Editors:}

JANSSENS and RIEDER [1] recently reported an inverse linear association between tuberculosis (TB) incidence and per capita gross domestic product, after analysing data from 171 World Health Organization (WHO) member states with paired data. We are in full agreement with the "take home" message that poverty alleviation must be an integral component of global TB control efforts. However, from an epidemiological perspective, additional factors may need to be considered to better understand the complex host-pathogen interplay at the population level.
Poverty facilitates the transmission of Mycobacterium tuberculosis, primarily through 1) its influence on living conditions, such as people living in overcrowded and poorly ventilated homes, 2) prolonged diagnostic delay and 3) increased vulnerability due to malnutrition and/or HIV infection [2, 3]. Although these ecological associations are widely recognised, it is frequently not supported by observations from individual studies. A potential explanation for this discrepancy is that beyond a certain threshold, the exact level of poverty has little influence on transmission risk, since living conditions remain conducive. The importance of living conditions rather than the exact level of poverty is supported by the rural/urban 
discrepancy in TB incidence rates reported in Norway by HEIMBECK [4] in 1928 and reviewed elsewhere [5]. Additional support for this "threshold effect" is provided by differences in the calculated annual risk of infection observed in two adjacent study communities, where socioeconomic conditions in the area with reduced transmission are sufficiently improved to affect general living conditions [6].

Therefore, from a TB transmission perspective it seems less informative to stratify extreme levels of poverty, and more informative to evaluate whether the available epidemiological evidence supports the existence of a threshold effect. Determination of a threshold effect will guide epidemiological thinking and potentially assist in identifying global poverty alleviation targets. Measuring child TB incidence rates as an epidemiological marker of ongoing transmission could be considered in future analyses, once more reliable WHO data becomes available. MYERS et al. [7] have found lower income, ethnicity and immigration status to be significantly associated with child TB incidence in California, USA.

Effective public health strategies remain critically important, even in the poorest of settings. However, the global distribution of the tuberculosis disease burden bears witness to the fact that extreme inequalities in wealth remain one of the key factors sustaining the tuberculosis epidemic.

\section{B.J. Marais, A.C. Hesseling and M.F. Cotton}

Dept of Paediatrics and Child Health, Desmond Tutu Tuberculosis Research Centre, Faculty of Health Sciences, Stellenbosch University, Tygerberg, South Africa.

\section{STATEMENT OF INTEREST}

None declared.

\section{REFERENCES}

1 Janssens JP, Rieder HL. An ecological analysis of incidence of tuberculosis and per capita gross domestic product. Eur Respir J 2008; 32: 1415-1416.

2 Marais BJ, Obihara CC, Warren RW, Schaaf HS, Gie RP, Donald PR. The burden of childhood tuberculosis: a public health perspective. Int J Tuberc Lung Dis 2005; 9: 1305-1313.

3 Marais BJ, Esser M, Godwin S, Rabie H, Cotton MF. Poverty and HIV in children a view from the Western Cape, South Africa. Ann N Y Acad Sci 2008; 1136: 21-27.

4 Heimbeck J. Tuberkuloseinfektion og tuberkulocevakcination [Tuberculosis infection and vaccination]. Tidsskr Norske Laegeforen 1928; 48: 945-961.

5 Bjarveit K. Olaf Scheele and Johannes Heimbeck: their contribution to understanding the pathogenesis and prevention of TB. Int J Tuberc Lung Dis 2003; 7: 306-311.

6 Kritzinger FE., den Boon S., Verver S., et al. No decrease in annual risk of tuberculosis infection in endemic area in Cape Town, South Africa. Trop Med Int Health 2008; (in press).

7 Myers WP, Westenhouse JL, Flood J, Riley LW. An ecological study of tuberculosis transmission in California. Am J Public Health 2006; 96: 685-690.

\section{Danger of using an unreliable classification system for preschool wheeze}

\section{To the Editors:}

The management of preschool children with wheezing disorders remains challenging. Clinicians should, therefore, welcome the decision by the European Respiratory Society to establish a Task Force to address this problem. The Task Force recommends that the terms episodic (viral) wheeze and multitrigger wheeze should be used to describe different clinical phenotypes of preschool wheeze [1]. However, the report acknowledges that there is large overlap in these two phenotypes and that patients can move from one phenotype to another [1]. Therefore, these two phenotypes are a long way from the "clear descriptions of patients" that the report suggests are needed for well-designed randomised controlled trials.

The clinical classification of wheeze phenotypes into episodic (viral) wheeze and multi-trigger wheeze is based on the assumption that wheeze associated with coryzal symptoms is virus induced, while wheeze in the absence of coryzal symptoms is not [2]. However, this fails to take into account the fact that most wheezing symptoms in preschool children are associated with viral infections [3] while, conversely, $>20 \%$ of asymptomatic asthmatic children aged 2-17 yrs test positive for rhinovirus in their respiratory secretions [4]. Basing classification on clinical judgment may therefore be hazardous.

To further complicate matters, for research purposes preschool phenotype classification based on clinical symptoms is usually based on a retrospective parental report $[5,6]$. When classification relies on potentially inaccurate clinical judgment of the presence or absence of viral infection, then adding a retrospective component could only further compromise the accuracy of classification system.

We agree with the authors of the Task Force report that a robust classification system has the potential to advance research and ultimately improve clinical decision making. However, we feel that the proposed classification based on episodic (viral) and multi-trigger wheeze is deeply flawed. Let us not succumb to the lure of this system for want of 